\title{
Enfoque y manejo de la embarazada hipotiroidea
}

\author{
Orlando Restrepo Ochoa*
}

RESUMEN: En años recientes, varios estudios realizados en animales y en humanos, han contribuido a entender mejor el papel que tiene el estado tiroideo materno en el desarrollo y la maduración fetal. Muchas mujeres tienen alto riesgo de desarrollar hipotiroidismo, y deben ser sometidas a tamización. La mejor prueba de laboratorio es la medición de la TSH sérica, seguida, si está elevada, de la determinación del índice de tiroxina libre (LT4), y de una titulación de anticuerpos contra la peroxidasa (TPO-Ac).

El principal riesgo que corren las gestantes hipotiroideas, es el de sufrir preeclampsia, y tener parto prematuro. La levotiroxina es el tratamiento de elección; muchas mujeres necesitan más tiroxina durante el embarazo, siendo necesario vigilar la función tiroidea durante toda la gestación, con el fin de hacer los ajustes requeridos a las dosis.

PALABRAS CLAVES: Hipotiroidismo, tiroiditis, levotiroxina, tirotropina, anticuerpos.

SUMMARY: In recent years, several studies in both animals and humans, have contributed to a better understanding the role that maternal thyroid status may play in fetal development and maduration. Some women are at high risk of developing hypothyroidism, and they should be screened. The best laboratory test is the serum TSH, followed, if elevated, by a free T4 index (LT4) and a TPO-ab titer.

The main risk for pregnant women hypothyroid is to suffer preeclampsia and have premature delivery. Levothyroxine is the treatment of choice; many women need more thyroxine during pregnancy, and surveillance of thyroid function is needed, throughout gestation to make dose adjustments when needed.

KEY WORDS: Hypothyroidism, thyroiditis, levothyroxine, thyrotropin, antibodies.

\section{Definición}

El hipotiroidismo es un síndrome clínico y bioquímico que resulta de una disminución en la producción de hormonas tiroideas, lo que lleva a una concentración sérica y tisular subnormal de ellas y que responde al tratamiento con hormona tiroidea.

\section{Frecuencia}

El hipotiroidismo es la alteración funcional más común de la glándula tiroides, presentándose en todas las edades con un predominio de 9 a 1 a favor de las mujeres.

En nuestro medio no existen estudios epidemiológicos que nos permitan determinar la magnitud del problema; en otros países, se presenta con una prevalencia del $1 \%$ en mujeres y del $0,1 \%$ en hombres. Después de los 60 años, esta prevalencia alcanza cifras del 9,6 al 20,3\%. Según estudios comunitarios, del 8 al $10 \%$ de las mujeres y del 1 al $2 \%$ de los hombres presentan hipotiroidismo subclínico, cursando la mayoría de ellos con anticuerpos antitiroideos positivos. Por otro lado, del 10 al $15 \%$ de las mujeres postmenopáusicas presentan TSH elevadas y anticuerpos antitiroideos y antimicrosomales positivos.

Recordemos igualmente, que el hipotiroidismo se presenta en 1 de cada 3.500 a 5.000 nacidos vivos (1-2).

* Profesor Grupo de Perinatología. Departamento de Obstetricia y Ginecología. Facultad de Medicina. Universidad de Antioquia.
Según publicaciones recientes, el hipotiroidismo clínico se presenta en 0,5 - 3 de cada 1.000 partos; igualmente, tres estudios de población le atribuyen una frecuencia bastante alta el hipotiroidismo subclínico (que antes no se diagnosticaba) durante el embarazo: del 1,9 al 25 por 1.000 embarazos (3-4).

\section{Etiología}

Las causas del hipotiroidismo son muchas, dando lugar a múltiples clasificaciones. Una clasificación académica sería (Ver cuadro 1): $(1,5)$.

Una clasificación práctica sería (Ver cuadro 2): $(2,6)$

Actualmente los tipos de hipotiroidismo más frecuentes en la práctica médica, tanto en la edad reproductiva como durante el embarazo, son los producidos por: tiroiditis de Hashimoto, postablativo (por tratamiento del hipertiroidismo con $I^{131}$ o tiroidectomía) y mixedema idiopático primario.

El hipotiroidismo central es menos frecuente y se debe investigar en toda paciente con enfermedades hipofisiarias e hipotalámicas o en aquellas que hayan sido sometidas previamente a cirugía o radioterapia de la región selar o áreas cercanas. Igualmente, la venoclisis con dopamina, las enfermedades graves o ambas, pueden suprimir la liberación de TSH y producir hipotiroidismo moderado. Durante el embarazo es posible encontrar ocasionalmente casos de ablación tiroidea debido a altas dosis de radiación externa para el manejo de linfomas y cáncer. 
Cuadro 1

\section{CAUSAS DE HIPOTIROIDISMO}

1. Hipotiroidismo primario o tiroideo

1.1 Tiroprivo o por destrucción de la glándula tiroides:

1.1.1 Autoinmune, forma atrófica no bociosa

1.1.2 Postablativo: tiroidectomía total y parcial, por $\mathrm{I}^{131}$, por radiación externa de cabeza y cuello (linfomas, cáncer).

1.1.3 Mixedema idiopático primario

1.1.4 Cretinismo atirótico esporádico

1.1.5 Por infiltración maligna: cáncer primario, linfomas tiroideos, enfermedad metastásica.

1.1.6 Por infiltración benigna: tiroiditis crónica fibrosa o Struma de Riedel, amiloidosis, escleroderma, cistinosis, hemocromatosis y sarcoidosis.

1.2 Por defectos en la biosíntesis de hormonas tiroideas, bociógeno o compensatorio:

1.2.1 Autoinmune, formas biociógenas

1.2.2 Por deficiencia y exceso de yodo (endémicoo iatrogénico)

1.2.3 Por drogas antitiroideas (PTU y Metimazol)

1.2.4 Por exposición o antitiroideos no farmacológicos: ácido paraminasalicílico, fenilbutazona, resorcinol, plantas crucíferas y casava.

1.2.5 Por defectos en enzimas necesarias para la síntesis de hormona tiroidea (bocio congénito) \& tipos del I al IV.

1.3 Por bloqueos en la secreción de hormonas tiroideas:

1.3.1 Uso de glucocorticoides

1.3.2 Uso de carbonato de litio

2. Hipotiroidismo central:

2.1 Secundario o hipofisiario o hipotirotrópico:

2.1.1 Defecto familiar aislado de células tirotrópicas

2.1.2 Panhipopituitarismo: tumoral, infiltrativo (hipófisis linfocítica autoinmune, sarcoidosis, histiocitosis, hemocromatosis), cirugía o radiación hipofisiaria, traumático o isquémico (síndrome de Sheehan y apoplejía pituitaria), venoclisis prolongada con dopamina y enfermedad grave.

2.2 Terciario o hipotalámico

2.2.1 Defecto aislado de las neuronas TRH positivas (niñas que reciben hormona de crecimiento).

2.2.2 Mixto (pacientes que reciben análogos de somatostatina)

2.2.3 Global (tumoral, infiltrativo, por radicación externa y traumático)

3. Síndrome de resistencia a las hormonas tiroideas

3.1 Resistencia periférica

3.2 Resistencia generalizada, hipofisiaria y periférica

3.3 Resistencia o insensibilidad tiroidea a la TSH (como defecto aislado o dentro del síndrome de Pseudohipoparatiroidismo).

4. Hipotiroidismo transitorio

4.1 Primeros seis meses de terapia con $I^{131}$ o postiroidectomía

4.2 Tiroiditis aguda o superativas (raras)

4.3 Tiroiditis subaguda. Presentan diferentes subtipos: dolorosa y granulomatosa de Quervain en su tercera fase; formas no dolorosas (más frecuentes) y dolorosas de las variedades espontánea y postparto de la tiroiditis linfocítica no Hashimoto; ocasionalmente la tiroiditis linfocítica crónica de Hashimoto.

\section{CAUSAS DE HIPOTIROIDISMO}

1. Primario o tiroideo (95\%)

1.1 Tiroprivo o por destrucción de la glándula tiroides:

1.1.1 Posfablativo: tratamiento con I131, postiroidectomía, por radicación externa cervical.

1.1.2 Mixedema idiopático primario

1.1.3 Cretinismo atirótico esporádico

1.2 Bociógeno o compensatorio:

1.2.1 Tiroiditis de Hashimoto

1.2.2 Deficiencia de yodo

1.2.3 Por yoduros

1.2.4 Por antitiroideos (PTU - Metimazol)

1.2.5 Por defectos en biosíntesis hormonal

2. Central o trofoprivos $(<5 \%)$

2.1 Secundario o hipofisiario (déficit de TSH)

2.2 Terciario o hipotalámico (déficit de TRH)

3. Resistencia periférica a las hormonas tiroideas

4. Hipotiroidismo transitorio

\section{Cuadro 3 \\ FARMACOS QUE PUEDEN CAUSAR HIPOTIROIDISMO Y SU MECANISMO}

Interferencia de la síntesis de hormona tiroidea, de su liberación o ambas:

- Drogas antitiroideas.(PTU - Metimazol)

- Yodo

- Litio

- Glucocorticoides

Eliminación elevada de Tiroxina (T4):

- Carbamacepina

- Fenitoína

- Rifampicina

Conversión disminuida de T4 a T3 e inhibición de la acción de la T3:

Amiodarona*

Interferencia de la absorción intestinal:

- Hidróxido de aluminio

- Colestiramina

- Sulfato ferroso

- Sucralfate

* La amiodarona es un fármaco muy eficaz para el manejo de arritmias cardíacas supraventriculares y ventriculares; debido a su alto contenido en yodo, causa hipotiroidismo clínico en el $8 \%$ de las pacientes. Otro $17 \%$ de ellas desarrollan elevaciones más leves de TSH y son asintomáticas. El hipotiroidismo materno se produce por disminución de la conversión de T4 a T3 y por inhibición de la acción de la T3. En el feto, la amiodarona causa tanto hipotiroidismo como hipertiroidismo, anormalidades neurológicas, retardo del crecimiento intrauterino (RCIU) y bradicardia fetal $(3,7-9)$. 
A veces se presenta hipotiroidismo transitorio en casos de tiroiditis subaguda indolora silenciosa. Durante la gestación es infrecuente encontrar hipotiroidismo congénito o síndromes de resistencia a las hormonas tiroideas (1-6).

Ahora, diversos medicamentos pueden causar hipotiroidismo mediante mecanismos diferentes (ver cuadro 3): (3).

\section{Diagnóstico}

Clínico: La deficiencia de hormona tiroidea afecta prácticamente todas las funciones del organismo. Los síntomas y signos se presentan de acuerdo con la edad de la paciente, con la velocidad con que se desarrolla el proceso y con la patología asociada. Se requiere alta sospecha clínica, ya que es difícil establecer el diagnóstico aún en casos avanzados.

En niñas y adolescentes llama la atención la estatura corta, los trastornos en el desarrollo sexual (incluyendo el retardo puberal en ambos sexos y la pubertad precoz verdadera sin aumento en la maduración ósea en las mujeres) y el retardo mental que acompaña al cretinismo.

En los adultos, las manifestaciones clínicas son bastante conocidas (ver tabla 1): (1-2).

El edema de las hipotiroideas se distingue del edema común en que no deja fóvea (mixedema). En la embarazada eutiroidea pueden encontrarse: constipación, piel fría y seca, cabello quebradizo, edema periorbitario, ronquera y disminución de la capacidad de concentración, todo lo cual hace más difícil el diagnóstico de hipotiroidismo; la intolerancia al frío es rara durante la gestación. Orientan hacia el diagnóstico: los reflejos osteotendinosos retardados o lentos, cardiomegalia y/o insuficiencia cardíaca congestiva.

El E.K.G. puede mostrar bradicardia, bajo voltaje generalizado y aplanamiento o inversión de la onda $\mathrm{T}$ en

Tabla 1

\section{MANIFESTACIONES CLINICAS DEL HIPOTIROIDISMO}

\begin{tabular}{|ll|}
\hline * Síntomas & * Signos \\
\hline Debilidad & $\begin{array}{l}\text { Xerostomía (piel áspera e } \\
\text { infiltrada) }\end{array}$ \\
Piel seca & Movimientos y lenguaje lentos \\
Letargia & Edema palpebral \\
Intolerancia al frío & Macroglosia \\
Disminución del sudor & Edema facial y periférico \\
Memoria alterada & Reflejos de relajación lenta \\
Constipación & Bradicardia \\
Aumento de peso & \\
(+ anorexia) & Piel pálida \\
Alopecía & \\
Ronquera & \\
\hline
\end{tabular}

* En orden decreciente de frecuencia
D II. Son relativamente comunes los derrames pleurales y pericárdicos, la anemia leve y la hipercolesterolemia.

La mayoría de las veces, la enfermedad tiroidea autoinmune se manifiesta en forma aislada, pero puede presentarse haciendo parte de síndromes autoinmunes poliglandulares que afectan varias glándulas endocrinas u otras estructuras como: insuficiencia suprarrenal, diabetes mellitus tipo I, anemia perniciosa, vitiligo, hipoparatiroidismo, candidiasis mucocutánea, hepatitis crónica activa, síndrome de malabsorción intestinal y miastenia gravis (3).

Es frecuente que las pacientes hipotiroideas leves presenten irregularidades menstruales, especialmente menorragias, antes de embarazarse; en los casos moderados o severos pueden presentarse amenorrea y galactorrea (3-5).

Ahora, en vista de la dificultad para establecer el diagnóstico sobre bases clínicas exclusivamente, algunos autores recomiendan la tamización rutinaria en pacientes con riesgo de desarrollar hipotiroidismo clínico o subclínico durante el embarazo, tal como se muestra en el cuadro $4(3,10-11)$.

Bioquímico: La detección del hipotiroidismo se basa clásicamente en la dosificación de la Tirotropina u hormona estimulante de la tiroides (TSH), de la Tiroxina (T4) y en menor grado de la Triyodotironina (T3).

En 1965 se comenzó a medir la TSH por radioinmunoanálisis, logrando con ello diferenciar el hipotiroidismo primario (TSH alta) del hipotiroidismo central (TSH normal o baja). Esta técnica llamada de primera generación utilizaba un solo anticuerpo y no era muy confiable para determinar el límite inferior del rango normal. En 1982, el desarrollo de anticuerpos monoclonales dirigidos a la TSH, aumenta notablemente la precisión diagnóstica en la medición de esta hormona; aquí se usan dos anticuerpos, quedando la TSh de la muestra a analizar, atrapada a manera de emparedado. Hoy en día, los análisis de segunda y tercera generación tienen una

\section{Cuadro 4 \\ DETECCION DE HIPOTIROIDISMO DURANTE EL EMBARAZO}

Riesgo Alto:

- Tratamiento previo de hipotiroidismo

- Irradiación cervical previa con dosis altas

- Antecedentes de tiroiditis postparto

- Bocio difuso o nodular

- Antecedentes familiares de enfermedad tiroidea

- Tratamiento con amiodarona

- Hipopituitarismo sospechado

- Diabetes Mellitus tipo I

Riesgo Moderado:

- Cualquier endocrinopatía

- Cualquier trastorno autoinmune

- Diversos medicamentos (ver cuadro 3)

- Exposición a sustancias químicas o industriales. Ejemplo: compuestos polibromados de bifenilo.

- Hiperlipidemia 
sensibilidad que extiende su rango de medición de 0,05 a más de $200 \mathrm{mU} / \mathrm{ml}$, sin necesidad de efectuar diluciones.

Por otro lado, cuando se ordenan T4 y T3, la mayoría de los laboratorios miden estas hormonas unidas a su proteína plasmática transportadora o sea T4 y T3 totales. Por tanto, se presenta dificultad en la interpretación de los resultados, debido a la variación en los niveles de las proteínas transportadoras; así por ejemplo, el síndrome nefrótico, el exceso de glucocorticoides exógeno o endógeno y la disminución idiopática de la globulina transportadora de tiroxina (TBG), llevan a una disminución de los niveles de T4 y T3 sin signos clínicos de hipotiroidismo. Actualmente están disponibles comercialmente en nuestro medio varios métodos para la medición de T4 y T3 libres (2-3).

De ahí, que la mejor prueba de laboratorio para diagnosticar hipotiroidismo es la medición de la TSH sérica. Si ésta se encuentra elevada, se deben solicitar la T4 libre y anticuerpos antitiroideos (sobre todo los anticuerpos contra peroxidasas tiroideas o TPO - Ac). Según la interpretación de los resultados tendremos:

$\begin{array}{ll}\text { Hipotiroidismo primario } & \text { - TSH elevada } \\ & \text { - T4 libre baja } \\ & \text { - T3 libre normal o baja } \\ \text { Hipotiroidismo central } & \text { TSH baja o inapropiadamente } \\ & \text { normal para el valor de T4. } \\ & - \text { T4 libre baja }\end{array}$

Hipotiroidismo subclínico - Ausencia de síntomas (o tiroides fallando o hipo- - TSH alta

tiroidismo compensado) • T4 libre normal

Síndrome de resistencia - TSH normal o alta

periférica a las hormonas - T4 y T3 libres altas ( $\sin$ signos tiroideas de tiroxicosis y más bien de hipotiroidismo).

Además del diagnóstico de hipotiroidismo, es importante tratar de aclarar la causa; para esto se deben ordenar determinaciones de anticuerpos antitiroideos, especialmente TPO-Ac, y si es del caso, otros exámenes paraclínicos. Veamos:

\section{Anticuerpos antitiroideos:}

Una de las áreas de mayor desarrollo en el campo del hipotiroidismo, es el de los fenómenos autoinmunes que lo producen o se le asocian. Actualmente, los principales grupos de anticuerpos descritos en el hipotiroidismo mediado inmunológicamente son:

1. Anticuerpos anti-tiroglobulina (TGB-Ac): en la tiroiditis de Hashimoto se encuentran títulos altos en el $85 \%$ de mujeres mayores de 20 años y en el $50 \%$ menores de 20 años. Pueden encontrarse títulos bajos en otras enfermedades tiroideas y en personas sanas.

2. Anticuerpos antiperoxidasa o antimicrosomales (TPO-Ac): Fijan complemento y por lo tanto son citotóxicos. Están presentes en casi todas las pacientes con tiroiditis de Hashimoto ( $100 \%$ en pacientes adultas) y en muchas con mixedema idiopático primario. Son los anticuerpos que más permiten diferenciar las formas autoinmunes de las no autoinmunes de los hipotiroidismos.
Pueden ser positivos en títulos bajos en otras enfermedades tiroideas.

3. Anticuerpos contra antígenos relacionados al receptor de TSH: Se han descrito muchos anticuerpos de este tipo; con respecto al hipotiroidismo, son importantes:

3.1 Inmunoglobulinas inhibitorias de la unión de la $T S H(T B I I)$ : Positivas en algunas pacientes con mixedema idiopático primario.

3.2 Inmunoglobulinas estimulantes del crecimiento tiroideo (TGI): Pueden inducir bocio sin estimular la producción hormonal. Son positivos en algunos pacientes con tiroiditis de Hashimoto y en enfermedades tiroideas que se acompañan de bocio.

3.3 Inmunoglobulinas bloqueadoras del crecimiento tiroideo (TGI-BLOC): Positivas en algunos pacientes con mixedema idiopático primario. Recordar, que frecuentemente coexisten varias de éstas y otras inmunoglobulinas en un mismo paciente (2-3).

Ecografía del tiroides: Evalúa tamaño, ecogenicidad, contornos y homogeneidad tiroideas; presencia de nódulos y su aspecto (sólidos, quísticos, mixtos) y de adenopatías cervicales. Recientemente se describen criterios ecográficos en la tiroiditis linfocítica crónica de Hashimoto.

Gamagrafía: Es una prueba de captación de yodo y su distribución topográfica, poco útil en el estudio del hipotiroidismo, aún en las formas bociógenas, la excepción es como parte de la prueba con supresión de T3 en el síndrome de resistencia generalizada a las hormonas tiroideas (prueba de captación de $\mathrm{I}^{131}$ con T3, contraindicada durante el embarazo) la cual da negativa, confirmando el diagnóstico.

Citología del tiroides por aspiración biopsia con aguja fina: Util solamente para definir la etiología de causas bociógenas de un hipotiroidismo (tiroiditis linfocítica crónica de Hashimoto, neoplasias malignas, amiloidosis, etc.) (2, 5-7).

Hemoleucograma: E1 30 a $40 \%$ de las hipotiroideas presentan anemia, la cual casi siempre es normocítica debido a la disminución de la eritropoyesis; a veces la anemia puede ser macrocítica por deficiencia de vitamina B12 y ácido fólico o microcítica por deficiencia de hierro. El recuento de leucocitos y plaquetas no se altera, pero en ocasiones hay anormalidad de la función plaquetaria, lo que favorece la hemorragia en la paciente.

Otros hallazgos de laboratorio: Aumento en las concentraciones de lípidos séricos (colesterol, LDL, triglicéridos), creatinina fosfokinasa (CPK) y anormalidades leves y reversibles en las pruebas de función hepática $(3,5-7)$.

Función tiroidea e interpretación de pruebas de función tiroidea durante el embarazo:

El embarazo produce cambios importantes, pero reversibles, que se detectan en las pruebas de función tiroidea; igualmente durante la gestación se alteran la producción, circulación y distribución de las hormonas tiroideas. De ahí que, para definir los cambios normales en los estudios de función tiroidea, se debe tener en cuenta la etapa específica del embarazo. Así por ejemplo, los cambios que ocurren durante el primer trimestre, pueden servir para garantizar un adecuado aporte de 
hormona tiroidea para el desarrollo fetal, antes de que madure su propio tiroides (12-13).

\section{Bocio:}

Durante el embarazo ocurre hipertrofia de la glándula tiroides, pero la frecuencia varía de acuerdo con la zona geográfica y del criterio clínico empleado para definir el bocio. A pesar de esto, la detección clínica de bocio en el embarazo es rara. En el estudio de Glinoer y col. (14) la presencia de bocio en el momento del parto fue del $15 \%$ (definido como un volumen total mayor de $23 \mathrm{ml}$ ). Según algunos autores, el crecimiento de la tiroides durante la gestación se debe a: hiperplasia del epitelio folicular, incremento en el tamaño y número de los acinos y a un aumento en la vascularización (15). Que ocurra o no bocio depende de la aptitud compensadora de la tiroides y de la concentración plasmática de yodo inorgánico. La carencia de yodo tiene importancia en la hipertrofia glandular.

\section{Metabolismo del yodo:}

La depuración renal del yodo aumenta tempranamente en el embarazo, continúa alta hasta el término y se normaliza a las seis semanas postparto. Lo anterior sumado al aumento de la filtración glomerular, a la hemodilución y el subsecuente aumento de la rata de aclaramiento metabólico del yodo, podrían producir una deficiencia del mineral, sino fuera compensado por el crecimiento glandular tanto metabólica como estructuralmente. Durante la gestación se necesitan más o menos $250 \mathrm{mcg} / \mathrm{d}$ ía de yodo por vía oral como requerimiento mínimo, el cual se absorbe en el tubo digestivo en forma de yoduro. La ingestión excesiva de yodo (más 2.000 $\mathrm{mcg} / \mathrm{día}$ ) puede producir bocios fetales enormes causantes de obstrucción traqueal neonatal, hipotiroidismo congénito, pasajero, retardo mental y muerte fetal.

Por otro lado, la deficiencia de yodo produce hipotiroidismo materno y fetal, lo cual provoca una deficiencia neurológica grave. En áreas con deficiencia de yodo como en China, se ha demostrado retrospectivamente, que sólo en los casos en que la madre fue tratada en el primer trimestre, la descendencia fue neurológicamente normal (12).

\section{Metabolismo de las hormonas tiroideas:}

La secreción normal de la glándula tiroides contiene aproximadamente $80 \%$ de levotiroxina (LT4) y $20 \%$ de T3, y a nivel tisular, mediante las deiodinasas tipo I a III, se transforma la T4 en T3, de acuerdo con las necesidades de los tejidos. La forma metabólicamente activa es la T3.

Ahora, según el sitio donde actúan, se conocen tres tipos de deiodinasas: 5-deiodinasas fenólicas tipo I y II, en el anillo exterior y 5-deiodinasas tirosílicas tipo III, en el anillo interior. La mayor parte de la T3 se deriva de la conversión periférica de T4 a T3 por la deiodinasa tipo I. Los tejidos con más alto contenido en esta enzima son: el hígado, los riñones y la tiroides. Esta enzima requiere el oligoelemento selenio, del cual carece la dieta de algunas zonas de China y Africa; de ahí que sea necesario una dieta adecuada en yodo y silenio para obtener una producción normal de hormona tiroidea (12).

La deiodinasa tipo II se encuentra principalmente en la hipófisis, SNC, grasa parda y placenta, aportando selectivamente T3 a estos tejidos. Esta enzima tiene mayor afinidad con T4 que con T3 reversa (rT3) y es resistente al propiltiouracilo (PTU); igualmente su actividad aumenta durante el hipotiroidismo, con el fin de mantener los niveles intracelulares de $\mathrm{T} 3$, a pesar del descenso en los niveles de T4 de tejidos fundamentales como el cerebro. La deiodinasa tipo I, por el contrario, es fácilmente inhibida por el PTU y su actividad disminuye en el hipotiroidismo.

La deiodinasa tipo III remueve un anillo interior de yodo y convierte T4 en el metabolito biológicamente inactivo rT3 y transforma la T3 en T2, la cual también es inactiva. La T3 estimula la actividad de la deiodinasa tipo III, la cual se halla en el cerebro, piel y placenta, cuando éstos se encuentran en desarrollo; la deiodinasa tipo III se encuentra en las células trofoblásticas de la placenta y su actividad se aumenta con el incremento de la masa placentaria. Se ha sugerido que la deiodinasa tipo III puede tener papel homeostático importante en la protección cerebral fetal y quizás también del feto en la situación del hipertiroidismo (con el yodo resultante de la desiodinación y la TRH, el feto construye su hormona tiroidea) $(1,3-4,6,16)$.

\section{Pruebas de función tiroidea:}

El primer cambio y el más notable es un aumento de las proteínas transportadoras inducido por la mayor producción de estrógenos durante el embarazo y por una reducción periférica de la rata de degradación de la globulina fijadora de Tiroxina (TBG); lo anterior, lleva a un aumento en las concentraciones séricas de T4 y T3 totales, pero la fracción libre de T4 y T3 es normal, aunque puede aumentar un poco en el primer trimestre y disminuir ligeramente en el tercero. Sólo la fracción libre es metabólicamente activa y representa $0,02 \%$ de la concentración total de T4 y $0,30 \%$ de la concentración total de T3; esta fracción libre regula la producción de hormona tiroidea por retroalimentación en el eje hipotálamo-hipofisiario $(1,4,12)$.

La TBG fija el $70 \%$ de T4 y T3; el remanente de hormona circulante está unida a la prealbúmina o transtiretina y una pequeña fracción a la albúmina. La elevación de la TBG se produce desde las dos primeras semanas de la gestación, aumenta linealmente hasta las 20 semanas y permanece en estos niveles hasta el parto, regresando a lo normal seis semanas después del mismo (ver figura 1).

Los estrógenos estimulan incrementos de ácido siálico en la TBG, lo que prolonga su vida media y aumentan su concentración sérica. Recordar que muchos medicamentos y trastornos adquiridos pueden alterar los niveles séricos de la TBG; ésta se aumenta con la hepatitis aguda, la metadona, el 5 fluorouracilo, la perfenacina y el clofibrato. Igualmente, la TBG se reduce a causa de cirrosis hepática, pérdida urinaria excesiva por síndrome nefrótico y medicamentos como andrógenos, glucocor- 
Figura 1

FUNCION TIROIDEA DURANTE EL EMBARAZO

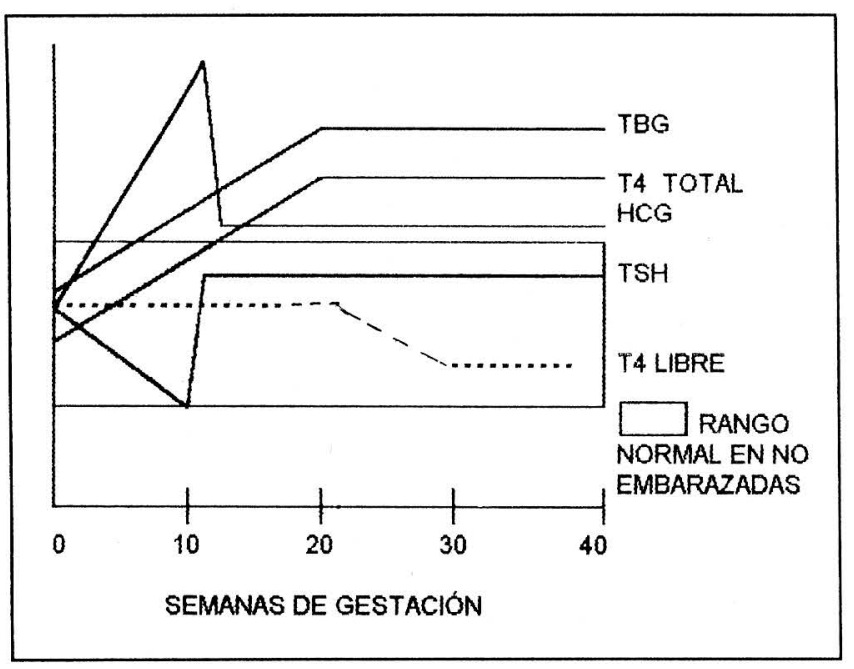

ticoides y L-asparaginasa. De ahí, que la importancia clínica de identificar las anormalidades en las proteínas de fijación, es fundamental para evitar diagnósticos y tratamientos erróneos (12).

- La concentración de TSH sérica se reduce en el primer trimestre, coincidiendo con los valores más altos de la gonadotropina coriónica humana ( $\mathrm{HCG}$ ) (ver figura 1). En Bélgica, se observaron 606 mujeres en un estudio de pruebas de función tiroidea seriadas que incluían análisis de alta sensibilidad. Esta investigación constituye el estudio más amplio sobre función tiroidea durante el embarazo disponible actualmente (12). La concentración sérica de TSH fue significativamente menor en el primer trimestre en comparación con los niveles de los otros dos trimestres; un porcentaje importante de esas 606 pacientes tuvo supresión de TSH sérica. La concentración sérica de T4 libre también fue significativamente alta en el primer trimestre, en comparación con el segundo y el tercero. Como dijimos antes, la elevación de la T4 libre puede ser importante para el desarrollo normal del feto.

- Por lo general, los niveles de tiroglobulina sérica se elevan y son proporcionales a la masa tiroidea. Los niveles de tiroglobulina son más altos en las mujeres que en los hombres y se incrementan más durante la gestación. En el estudio prospectivo de las 606 embarazadas en Bélgica, los niveles del primer trimestre estaban por arriba de lo normal y dos terceras partes de ellas tuvieron un aumento significativo entre el primer trimestre y el parto. El incremento más grande se observó en el tercer trimestre.

Los niveles de tiroglobulina no se correlacionaron con la concentración sérica de T3, T4, HCG o las concentraciones de yodo. En el parto se observó una modesta correlación entre la tiroglobulina, la TSH y la proporción T3/T4. En Bélgica, casi el 75\% de las mujeres experimentó un aumento en el volumen de la tiroides, teniendo en cuenta, que es un país con un consumo marginal de yodo.

\section{Anticuerpos antitiroideos:}

Se detectan en el 3\% de las mujeres no embarazadas y entre el 5 y el $20 \%$ de las embarazadas, dependiendo del método utilizado. La existencia de anticuerpos antitiroideos contra peroxidasa (TPO-Ac) en la sangre indica enfermedad tiroidea o una alta probabilidad de que ésta se encuentra en desarrollo. La propensión a formar estos anticuerpos contra TPO se hereda como una característica autosómica dominante en las mujeres, pero en los hombres tiene escasa penetrancia.

Por otro lado, su positividad incrementa la posibilidad de aborto espontáneo y sobre todo de tiroiditis postparto; muchas mujeres tendrán positivos estos anticuerpos durante el embarazo, pero no después del parto y otras desarrollarán enfermedad tiroidea crónica $(1-3,12,17)$.

\section{Interacciones materno-placentario-fetales:}

La tiroides fetal humana es capaz de sintetizar hormona tiroidea entre las 10 y 12 semanas de gestación. El sistema hipotálamo, hipófisis fetal es capaz de sintetizar hormona liberadora de Tirotropina (TRH) y TSH desde las ocho-diez semanas de gestación; igualmente las comunicaciones vasculares entre el hipotálamo y la hipófisis aparecen entre las 11 y 12 semanas de embarazo (4).

La placenta es libremente permeable a la TRH, inmunoglobulinas $\operatorname{IgG}$ y drogas antitiroideas como el PTU, el metimazol yodo y propranolol (12, 18-19). La placenta es impermeable a TSH y T3 y deja pasar pequeñas cantidades de T4 (ver tabla 2): (20).

Estudios recientes en animales y en humanos sugieren que el estado tiroideo de la madre y las pequeñas cantidades de hormonas tiroideas que atraviesan la placenta, tienen importancia para la madurez del cerebro fetal ( 12 , 21). En humanos no se entiende bien porque algunas mujeres hipotiroideas, aún sin tratamiento, pueden dar a luz lactantes aparentemente normales. La mayoría de los neonatos con hipotiroidismo congénito no presentan síntomas ni aspecto de hipotiroidismo después del nacimiento. Esto se ha utilizado como prueba de que el eje hipotálamo hipófisis-tiroides fetal y el desarrollo y maduración del feto, son independientes de la madre (ver figura 2) (22). En el primer trimestre la HCG placentaria es un estimulador leve de la tiroides materna. La TRH materna atraviesa la placenta, pero la TSH no. El paso de T4 es mínimo y el de T3 nulo. Sin embargo, la razón para

Tabla 2

PERMEABILIDAD PLACENTARIA

\begin{tabular}{|ll|}
\hline Sustancia & Permeabilidad \\
\hline I (-) & ++++ \\
TRH & +++ \\
Antitiroideos & +++ \\
Anticuerpos de síntesis & +++ \\
T3 & 0 \\
T4 & + \\
TSH & 0 \\
\hline
\end{tabular}


que los neonatos hipotiroideos luzcan normales al nacer, parece deberse a que la madre les transfirió T4 en cantidad suficiente para prevenir las manifestaciones del hipotiroidismo fetal (la T4 materna normal puede compensar la insuficiente producción de la hormona tiroidea fetal, pero en caso de insuficiencia tanto fetal como materna, es probable la presentación de anormalidades neurológicas).

Después del nacimiento, cuando ya no está disponible la T4 materna, se desarrolla el hipotiroidismo y causa deficiencias cognitivas potencialmente graves si no se da tratamiento ' $(12,22)$.

\section{Efectos del hipotiroidismo durante el embarazo:}

Se describe alta incidencia de abortos espontáneos en el primer trimestre, muertes intrauterinas, retraso mental, malformaciones congénitas (anormales físicas) y amenaza de parto prematuro $(3,23)$. Reportes recientes, no confirman la alta mortalidad perinatal y las malformaciones congénitas descritas en otros estudios en la mujer hipotiroidea (3-4).

Ahora, publicaciones de los últimos años presentan numerosas pruebas de que las mujeres con anticuerpos antitiroideos contra peroxidasas (o antinicrosomales) y contra tiroglobulina, tienen una posibilidad dos veces mayor de sufrir un aborto y desarrollar tiroiditis postparto (TPP), sin importar el estado de función tiroidea. No se sabe si lo anterior, es por efecto tóxico directo de los anticuerpos antitiroideos, o si éstos sólo son marcadores de autoinmunidad anormal en pacientes que también tienen otros anticuerpos identificados como causa de abortos recurrentes, como los anticuerpos antifosfolípidos (3-4).

De la revisión de los últimos estudios podemos concluir, que el principal riesgo que corren quienes al inicio del embarazo son hipotiroideas pero alcanzan el estado eutiroideo mediante tratamiento, es el de sufrir

Figura 2

\section{RELACIONES TIROIDEAS MATERNO PLACENTARIAS Y FETALES}

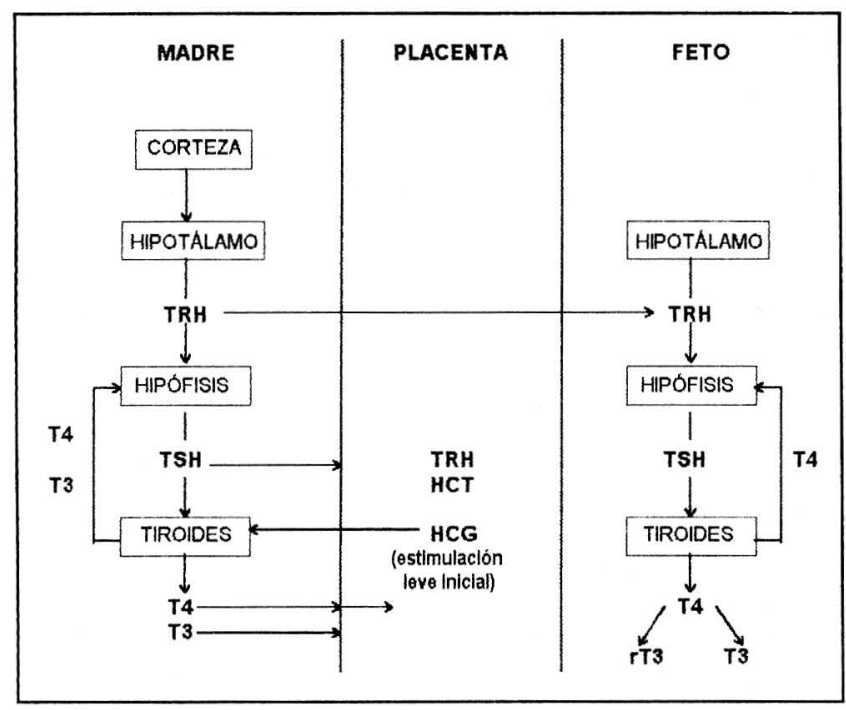

hipertensión inducida por el embarazo (HIE) en el 15$30 \%$ de los casos. Las mujeres que permanecen con hipotiroidismo al término, se enfrentan a un riesgo mayor de padecer HIE y partos prematuros (22-44\%), al igual que desprendimiento prematuro de placenta (DPP), obitos fetales, hemorragia postparto y anemia. La alta incidencia de bajo peso al nacer se relaciona principalmente con HIE, la cual a su vez ocasiona parto prematuro con la correspondiente morbimortalidad y alto costo. La severidad de la HIE y la incidencia de complicaciones perinatales es mayor en las embarazadas con hipotiroidismo clínico y grave que en quienes presentan hipotiroidismo subclínico (24-29).

En 1995, Wasserstrum y Anania (28) correlacionan la frecuencia de sufrimiento fetal agudo (SFA) durante el trabajo de parto con las pruebas de función tiroidea al inicio del embarazo, pero no cerca al término. Al parecer el hipotiroidismo grave al comienzo de la gestación, de alguna manera ejerce efectos irreversibles en la unidad vascular placentaria, los cuales no son corregidos por reemplazo subsecuente de $\mathrm{T} 4$ y sólo se manifiestan durante la tensión del trabajo de parto, sin que afecten el crecimiento fetal ni el postnatal. Igualmente, aunque no hubo correlación estadística, los casos de S.F.A. se presentaron en madres con hipotiroidismo grave al término. Este informe, a diferencia de los demás estudios recientes, no encuentra casos de HIE.

Por tanto, el tratamiento y la vigilancia estrecha para asegurar normalización continua de las pruebas de función tiroidea, redundarán en prevención o disminución significativa de las complicaciones perinatales.

Las pacientes que padecen enfermedades concomitantes, especialmente diabetes, hipertensión crónica y anemia, deben recibir tratamiento adecuado para dichos trastornos y vigilancia. Aún no se sabe por qué la hipertensión es más frecuente cuando hay trastornos tiroideos; las pacientes con hipotiroidismo tienen gasto cardíaco disminuido y resistencia periférica aumentada, tal vez a causa de una respuesta alfa adrenérgica a un aumento en el tono nervioso simpático.

Los informes iniciales sobre retardo del desarrollo físico y menores cocientes de inteligencia en los hijos de madres hipotiroideas, no han sido confirmados en otras investigaciones; los datos disponibles demuestran que el desarrollo de los niños, tanto físico como mental, ha sido normal en seguimiento hasta los 10 años de edad (30). Sin embargo, Pop y col (31) encuentran que los hijos de mujeres eutiroideas con títulos altos de TPO-Ac tenían IQ menores que los hijos de madres (también eutiroideas) con títulos de TPO-Ac negativos. De ahí que se requiera estudiar más a fondo los efectos de los anticuerpos antitiroideos sobre el feto.

\section{Tratamiento:}

Actualmente el hipotiroidismo se diagnostica y trata desde etapas tempranas del embarazo; lo anterior aunado a una adecuada atención perinatal, mejora los resultados.

Lo óptimo es que las mujeres alcancen el estado eutiroideo antes de embarazarse, manteniéndolo a lo largo de toda la gestación. Se deben reajustar las dosis 
terapéuticas cuantas veces sea necesario, ya que como veremos más adelante, muchas pacientes requieren mayores dosis de reemplazo durante la gestación.

El tratamiento se basa en la suplencia con LevoTiroxina sódica sintética (LT4S). Recordar que la tiroides secreta $80 \%$ de LT4 y $20 \%$ de T3. Las ventajas del manejo con LT4S, son:

1. Es la forma que secreta la tiroides fisiológicamente

2. La estabilidad en los niveles hormonales de T3 y T4

3. La prolongada vida media del producto (ocho días), lo cual protege contra olvidos en la ingestión de la droga. Se debe administrar en una sola toma en ayunas, con una absorción del $80 \%$.

4. La obtención de niveles normales de T3 (por conversión periférica de T4 a T3), forma metabólicamente activa que regula la síntesis y secreción de TSH en la hipófisis. La terapia con T3 causa más iatrogenia debido a su rápida absorción; igualmente, al parecer esta forma exógena es menos eficiente en la regulación del eje hipotálamo-hipófisis. La dosis promedio es de 100-150 mcg/día. Si la paciente tiene una enfermedad cardíaca o es anciana, se inician dosis bajas ( $25 \mathrm{mcg} / \mathrm{día})$; esta dosis se aumenta en $25 \mathrm{mcg} /$ día cada 4-6 semanas, ya que de otra forma se corre el riesgo de desencadenar una crisis anginosa, arritmias o falla cardíaca. La dosis total en estas pacientes fluctúa entre 50 y $75 \mathrm{mcg} /$ día.

Recordar que a mayor profundidad del hipotiroidismo, los aumentos deben hacerse más lentamente, sobre todo en los hipotiroidismos primarios. El tratamiento de los hipotiroidismos centrales también se hace con LT4S aunque la dosis es menor que en los hipotiroidismos de origen tiroideo. Los síndromes de resistencia a la hormona tiroidea se manejan igualmente con LT4S, teniendo en cuenta que la resistencia o insensibilidad a la TSh usualmente no mejora. Los hipotiroidismos transitorios se tratan con LT4S o se observan.

En cuanto al hipotiroidismo subclínico, se debe evaluar la TSH según la edad. En mujeres con TSH>10 mU/ $\mathrm{ml}$ y anticuerpos antitiroideos positivos, del 1 al $20 \%$ por año (promedio de 7\%) evolucionan hacia hipotiroidismo definitivo, sin que esto signifique que la presencia de anticuerpos antitiroideos per se, sean equivalentes a falla tiroidea. Se dan dosis pequeñas de $25 \mathrm{mcg} / \mathrm{día}$, ya que la administración de LT4S es segura, simple, barata y previene el hipotiroidismo clínico $(1,32)$.

En nuestro medio se consiguen comercialmente:

- Proloid: T4 + T3. Tabletas de $65 \mathrm{mg}$ de tiroglobulina pura, caja por 100 tabletas. Es barato, efectivo, bien tolerado, pero ocasionalmente hay variaciones en su actividad biológica y fluctuaciones en los picos de mayor actividad hormonal, lo que representa un peligro en ancianos o en pacientes con enfermedad cardíaca.

- Cynomel: T3. Tabletas de $25 \mathrm{mcg}$, en caja por 50 tabletas. Los problemas antes mencionados son más notables, tiene una vida media corta y hay que suministrarlo en dosis diarias fraccionadas.

- Euthroid - 2: T4 + T3, en proporción de cuatro partes de levotiroxina sódica por 1 de T3 (120 mcg/30 mcg), caja por 48 tabletas. No tiene ventajas sobre la LT4S y presenta fluctuaciones en niveles de T3.
- Eltroxin: T4. Tabletas de $50 \mathrm{mcg}$ en frasco por 50 tabletas y tabletas de 100 mcg en frasco por 100 tabletas de tiroxina sódica anhidra.

- Tiroxin: T4. Tabletas de $50 \mathrm{mcg}$ en caja por 50 tabletas y tabletas de $100 \mathrm{mcg}$ en caja de 80 tabletas de levo-tiroxina sódica.

- Euthyrox: T4. Tabletas de $50 \mathrm{mcg}$ en caja x 50 tabletas y tabletas de $100 \mathrm{mcg}$ en caja x 50 tabletas de levo-tiroxina sódica.

Equivalencia: $100 \mathrm{mcg}$ de T4 $=65 \mathrm{mg}$ de Proloid $=25$ mcg de T3 = 1/2 tableta de Euthroid.

Desde 1984, empiezan a publicarse informes acerca de la necesidad de aumentar la dosis de T4 (50 a 75\%) durante el embarazo. (3-4, 32-34). La revisión más grande en este aspecto la realiza Kaplan en 1992 (35): El estudia 65 mujeres con 77 gestaciones y las separa en dos grupos: 36 tenían hipotiroidismo secundario a tiroidectomía, ablación con yodo radiactivo o ambas cosas y 29 secundario a tiroiditis crónica de Hashimoto. E1 76\% del primer grupo (promedio de incremento de 50 $\mathrm{mcg}$ ), y $47 \%$ del grupo de tiroiditis de Hashimoto (promedio de incremento de $28 \mathrm{mcg}$ ), requirieron aumento en la dosis de LT4, la mayoría de ellas durante el primer trimestre. No obstante, $33 \%$ de las pacientes que tuvieron concentraciones de TSH normales en el primer trimestre, requirieron reajuste de la dosis en etapas más avanzadas de la gestación, lo que confirma la necesidad de vigilar a las pacientes durante todo el embarazo.

A partir de estos datos, Kaplan sugirió que la concentración inicial de la TSH durante la gestación, puede utilizarse como base para calcular la dosis de LT4 requerida para normalizar los aumentos de TSH. En pacientes con diagnóstico durante el embarazo, se administrará una dosis inicial de $2 \mathrm{mcg} / \mathrm{kg}$ de peso (ya que la producción diaria total de T4 depende de la masa corporal) ó 150 $\mathrm{mcg} /$ día. Para pacientes con diagnóstico previo al embarazo, pueden utilizarse los lineamientos de Kaplan (ver cuadro 5) (35).

Las razones para el aumento de la LT4 son: aumento en la concentración sérica de la TBG, incremento de la masa corporal, la necesidad de saturar las cantidades adicionales de TBG que se acumulan durante el primer trimestre, la mayor absorción intestinal de T4 (factor más tardío) y la muy alta actividad de la deiodinasa III placentaria, lo que puede ocasionar aumento de la eliminación de T4 durante el embarazo $(3,32)$.

Se requiere por tanto realizar mediciones de la función tiroidea cada cuatro semanas, hasta que la TSH vuelva a los valores normales y la T4 se encuentre en el tercio superior de los valores normales. La TSH puede requerir más de ocho semanas para retornar a los valores

\section{Cuadro 5}

\section{TRATAMIENTO DEL HIPOTIROIDISMO}

Dosis inicial: $150 \mathrm{mcg}$ ó $2 \mathrm{mcg} / \mathrm{kg} /$ día

Reajustes:

$\mathrm{TSH} \uparrow$ pero $<10 \mathrm{mU} / \mathrm{ml} \rightarrow$ agregar $50 \mathrm{mcg} /$ día

$\mathrm{TSH}>10$, pero $<20 \mathrm{mU} / \mathrm{ml} \rightarrow$ agregar $75 \mathrm{mcg} /$ día

$\mathrm{TSH}>20 \mathrm{mU} / \mathrm{ml}$ 
basales (18). Luego del parto, la dosis de LT4 debe reducirse a los valores pre-embarazo, y se debe realizar control de TSH a las seis-ocho semanas postparto, para verificar si fue adecuado el cambio de dosis.

Hipotiroidismo congénito (H.C.): Cada vez se da más importancia al diagnóstico precoz de hipotiroidismo congénito. La preocupación sobre este problema se basa en la comprobación de que un manejo oportuno y adecuado, iniciado antes de los tres meses de edad, puede evitar en el niño un retardo mental irreversible. La relativa frecuencia del problema (1/3.500 - 5.000 recién nacidos) y la carencia de signos clínicos confiables en el neonato hipotiroideo, han llevado a que la mayoría de los países hayan adoptado programas de detección masiva en el período neonatal; para ello se emplean tiras de papel de filtro impregnadas de sangre, tres a cinco días postnacimiento (se procesan TSH, T4 o idealmente ambas). La dosis de reemplazo en niños menores de 6 meses es de $8-10 \mathrm{mcg} / \mathrm{kg} /$ día de $\mathrm{T} 4$, disminuyendo la dosis $/ \mathrm{kg}$ a medida que el bebé crece. La dosis debe ajustarse individualmente con el fin de mantener el nivel de $\mathrm{T} 4$ en el límite superior normal y normalizar la TSH. Las anteriores medidas tienen por objetivo, que los patrones de desarrollo mental y físicos sean normales $(2,6)$.

La mayoría de los casos son esporádicos y son debidos a una glándula ectópica o agenesia tiroidea. Las alteraciones familiares en la biosíntesis de hormona tiroidea son raras, pero los hijos de estas familias están en riesgo.
La ingestión materna de yoduros y drogas antitiroideas pueden causar bocios fetales enormes, produciendo obstrucción traqueal neonatal, hipotiroidismo congénito, retardo mental y muerte fetal. Juegan papel importante igualmente, los anticuerpos antitiroideos (TSI o inmunoglobulinas estimulantes del tiroides y los bloqueadores del receptor de TSH) (36-37).

Las características clásicas del H.C. incluyen: letargia, depresión del puente nasal, macroglosia, hernia umbilical, piel seca, hipotonía muscular, hiporreflexia, retardo en el desarrollo neurológico y en la edad ósea, además de disgenesia epifisiaria. Recordar que dicho cuadro es la excepción y no la regla.

Actualmente pueden diagnosticarse los bocios fetales mediante el ultrasonido, a partir del segundo trimestre de gestación. Igualmente puede determinarse la función tiroidea fetal por cordocentesis y diagnosticar hipotiroidismo fetal in útero. Una vez hecho el diagnóstico, el tratamiento se lleva a cabo con inyecciones intraamnióticas de LT4; la dosis recomendada de ésta, varía entre 250 y $600 \mathrm{mcg}$ semanal, pero se ha visto que con $250 \mathrm{mcg} / \mathrm{semana}$ es suficiente para disminuir el bocio fetal hasta alcanzar el tamaño normal y normalizar la función tiroidea. La cordocentesis se puede repetir una semana después de iniciar la terapia y a las 35 semanas de gestación (36, 38-41). Las mediciones de T4, rT3 y TSH en el líquido amniótico, no predicen el estado tiroideo fetal en embarazos de ARO.

\section{BIBLIOGRAFIA}

1. Latorre SG. Enfoque y manejo del paciente con hipotiroidismo. Una visión etiológica. En: Tobón A., L.I. ed. Actualización en medicina interna. Primera edición. Medellín. Editorial Universidad de Antioquia; 1995; 188-199.

2. Uribe LF. Hipotiroidismo. En: Alvarez H., Betancur J., Correa G y col. Actualización en medicina interna. Primera edición. Medellín. Editorial Universidad de Antioquia; 1991; 139-147.

3. Montoro MN. Tratamiento del hipotiroidismo durante el embarazo. Clin Obst y Ginecol. 1997; 1: 59-72.

4. Mestman JH., Goodwin TM., Montoro MN. Thiroid disorders of pregnancy. Endocrinol Metab Clin N Am. 1995; 24: 41-71.

5. Larsen PR. Tiroides - Hipotiroidismo y mixedema. En: Wyngaarden JB., Smith LH., Bennett JC ed. Tratado de Medicina Interna de Cecil. 19 edición. México. Editorial Interamericana 1994; (II): 1468-1472.

6. Foz Sala M., Sanmartí Sala A., Lucas Martín A. Enfermedades del tiroides. Hipotiroidismo. En: Farreras Valenti P., Rozman C. Medicina Interna. 13 edición. Barcelona (España). Mosby/Doyma libros: 1995; (II): 2053-2073

7. Fitzgerald PA. Endocrinología. Enfermedades de la glándula tiroides. En: Tierney LM., McPhee SJ., Papadakis MA. Diagnóstico clínico y tratamiento. 32a edición. México. Manual Moderno 1997; 1000-1006.

8. Magee LA., Downar E., Sermer M et al. Pregnancy outcome after gestational exposure to amiodarone in Canada. Am J Obstet Gynecol 1995; 172(4Pt1): 1307-1311.

9. De Catle L., De Wolf D., Smitz J et al. Fetal hypothyroidism as a complication of amiodarone treatment for persistent fetal supraventricular tachycardia. Prenat. Diagn 1994; 14(8): 762-765.

10. Glinoer D., Riahi M., Grun JP., Kinthaert J. Risk of subclinical hypothyroidism in pregnant women with asymptomatic autoinmune thyroid disorders. J Clin Endocrinol Metab 1994; 79(1): 197-204.

11. Alvarez MM., Roman SH., Drexier AJ., Robertson C., Stagnaro GA. Long term prospective study of postpartum thyroid dysfunction in women with insulin dependent diabetes mellitus (see comments). J Clin Endocrinol Metab 1994; 79(1): 10-16.

12. Brent GA. Función tiroidea materna: Interpretación de pruebas de función tiroidea en el embarazo. Clin Obstet y Ginecol. 1997; 1: 3-14.
13. Burrow GN., Fisher Da., Larsen PR. Maternal and fetal thyroid fucntion. N Engl J Med 1994; 331: 1072-1078.

14. Glinoer D., De Nayer P., Bourdoux P. Regulation of maternal thyroid during pregnancy. J Clin Endocrinol Metab 1990; 71: 276-287.

15. Tunbridge W., Hall R. Función del tiroides en el embarazo. Obstetricia y Ginecol Temas Actuales. 1975; 2: 379-391.

16. Koopdonk - Kool JM., de Vijider JJ., Veenboer GJ et al. Type II and type III delodinase activity in human placenta as a function of gestational age. J Clin Endocrinol Metab 1996; 8 (6): 2154-2158.

17. Lazarus JH., Hail R., Othman $S$ et al. The clinical spectrum of postpartum thyroid disease. Q.JM. 1996; 89(6): 429-435.

18. Thomas R., Reid RL. Thyroid disease and reproductive dysfunction. A review Obstet Gynecol. 1987; 70(5): 789-798.

19. Lenaerts LA., Bonnyns M. Glande thyroide et fonction sexualle féminine. J. Gyn Biol Repr. 1982; 11: 677-684.

20. Polk DH., Fisher DA. Fetal and neonatal thyroid physiology. En: Polin RA., Fox WW. Fetal and neonatal physiology. 2a edition. Philadelphia, Pennsylvania. WB Saunders Company 1998; (2): 24602467.

21. Pacaud D., Huot C., Gatterau A et al. Outcome in three siblings with antibody-mediated transient congenital hypothyroidism. J Pediatr 1995; 127(2): 275-277.

22. Hollingsworth DR. Trastornos endocrinos del embarazo- Tiroides. En: Creasy Rh., Resnik R. Medicina Materno Fetal. Buenos Aires (Argentina). Editorial Médica Panamericana 1987; 933-935.

23. Grossman CM., Morton WE., Nussbaum RH. Hypothyroidism and spontaneous abortions among Hanford, Washington, down winders. Arch. Environ. Health 1996; 51(3): 175-176.

24. .Montoro MN., Collea JV., Frasier SD et al. Successful outcome of pregnancy in women with hypothyroidism. Ann Intern Med 1981; 94 : 31-34.

25. Davis LE., Leveno KJ., Cunningham FG. Hypothyroidism complicating pregnancy. Obstet Gynecol. 1988; 72: 108-112.

26. Buckshee K., Kriplani A., Kapil A et al. Hypothyroidism complicating pregnancy. Aust. NZ. J Obstet Gynecol. 1992; 32: 240-242. 


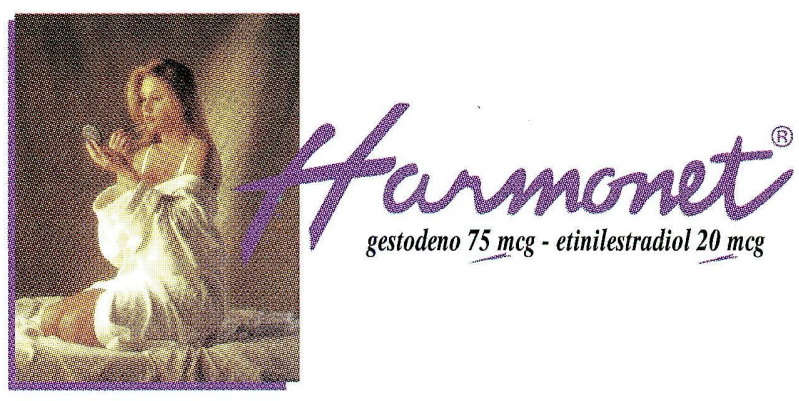

FORMULA

Cada gragea contiene: Gestodeno $75 \mathrm{mcg}$, Etinilestradiol $20 \mathrm{mcg}$, Lactosa $37,155 \mathrm{mg}$, azúcar 19,66 mg almidón de maíz $15,5 \mathrm{mg}$, carbonato de calcio $8,697 \mathrm{mg}$, talco $4,242 \mathrm{mg}$ polietilenglicol $60002,18 \mathrm{mg}$, povidona K-25 1,7 $\mathrm{mg}$, estearato de magnesio $550 \mathrm{mcg}$, povidona K-90 $171 \mathrm{mcg}$, cera E $50 \mathrm{mcg}$.

INDICACIONES

Harmonet está indicado para la prevención del embarazo en mujeres que deciden utilizar este método.

\section{POSOLOGIA Y FORMA DE ADMINISTRACION}

Para lograr una eficacia anticonceptiva óptima, HARMONET deberá ingerirse diariamente según las indicaciones y con intervalos diarios que no excedan las 24 horas. Debe instruirse a la paciente para que tome las grageas todos los días a la misma hora, preferiblemente con la comida de la noche o bien antes de acostarse.

\section{CONTRAINDICACIONES}

Harmonet está contraindicado en las mujeres que presenten:

Antedentes o diagnóstico de trastornos trombóticos arteriales o venosos, trastornos embólicos o situaciones que pudieran predisponer a la paciente (por ejemplo, defectos de la coagulación, valvulopatias cardíacas fibrilación auricular): transtornos agudos o crónicos de la función hepática (incluyéndose entre éstos el síndrome de Dubinauricular); transtornos agudos o cronicos de la función hepática (incluyendose entre estos el sindrome de Dubinidiopática o de prurito importante durante el embarazo; antecedentes o diagnóstico conocido o sospechado de neoplasias hormonodependientes ( por ejemplo, cancer de mama o de endometrio); trastornos del metabolismo neoplasias hormonodependientes ( por ejemplo, cancer de mama o de endometrio); trastornos del metabolismo lipidico; anemia faciciorme; diabetes melitus con alteraciones vasculares; antecedentes de herpes gestacional; sospechado; hipersensibilidad a cualquiera de los componentes de Harmonet.

\section{EFECTOS SECUNDARIOS}

Los siguientes efectos secundarios se han registrado en un total de 1338 pacientes que recibieron Harmonet durante el curso de tres estudios clínicos:

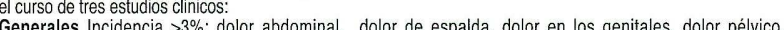
Generales Incid 1\%: do dor abdomina, dolor de espelvico. licida pesadez en las extremidades, infecciones, malestar, monillasis, artitis reumatoidea. Sistema Cardiovascular (rombosis de las venas profundas solocos, hipertension, palpilaciones, taquicardia, tromboembolia, tromboflebitis, vasodilatación, y otros transtornos cardiovasculares. Sistema Digestivo Incidencia <3\%: Náuseas. Incidencia 1\%-3\%: Vómito. Incidencia <1\%: colecistis, diarrea, flatulencia, transtornos vesiculares, gastritis, gastroenteritis, transtornos gastrointestinales, hepatopatia, aumento del apetito estomatitis. Sistema Metabolico Incidencia $<1 \%$ edema aumento o pérdida del peso. Sistema Nervioso Incidencia $>3 \%$ : Cefaleas, nerviosismo. Incidencia 1\%-3\%: Depresión, mareos, alteraciones en la libido. Incidencia < $1 \%$ : amnesia, ataxia, hostilidad, parestesia, transtornos en el suen, somnolencia, sudo sinusitis. Derma otros tratal transitora. Sis dema. ncidencia <

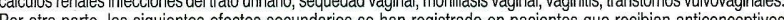
Por otra parte, los siguientes efectos secundarios se han registrado en pacientes que recibian anticonceptivos orales y se consideraron relacionados con la droga administrada.Nauseas, Vomilos, sintomas gastrointestinales, (Tales como collcos abdominales e inlamación), sangrado intermenstrual, goleo, alteraciones en el hujo mensirual, amenorrea, inlerthidad temporaria con posterioridad a la desconthuación del tratamiento, edema, melasma que puede persistir, aumento o disminución de peso, alteraciones en la erosion y secreción cervical, disminución en el volumen de leche en el postparto inmediato, ictericia colestática, migrana, eritema (alérgico), depresión mental, menor tolerancia a los carbohidratos, candidiasis vaginal, acentuación de la curvatura de la córnea, intolerancia a los lentes de contacto, cambio en las mamas: tensión, aumento de tamaño, secreción. Existen evidencias de una posible relación entre los siguientes efectos secundarios y la utilización de anticonceptivos orales, aunque aún debe confirmarse esta información: Trombosis mesentérica, Trombosis retiniana. Los siguientes efectos secundarios se han registrado en pacientes que recibían anticonceptivos orales, pero su asociación no ha sido aún confirmada ni rechazada: Anomalías congénitas, Síndrome premestrual, cataratas, neuritis óptica, cambios en el apetito, síndrome similar a la cistitis, cefaleas, nenviosismo, mareos, hirsutismo, pérdida del cabello, eritema multiforme, eritema nodoso, erupción hemorrágica, vaginitis, disminución de la función renal, síndrome urémico hemolítico, síndrome de BuddChiari, acné, cambios en la libido. colitis, enfermedad cerebrovascular, con prolapso de la válvula mitral, síndrome similares a lupus.

Para mayor información, véanse las advertencias y precauciones.

SOBREDOSIS

La sobredosis puede causar náuseas o vómitos; en las mujeres puede producirse sangrado por supresión. En niños, no se han registrado efectos graves después de la utilización de altas dosis de anticonceptivos orales.

PRESENTACION

Envase con 21 grageas. Registro INVIMA 006606
27. Lung AS., Millar LK., Koonings PP et al. Perinatal outcome in hypothyroidism pregnancy. Obstet Gynecol. 1993; 81: 349-353.

28. Wasserstrum N., Anania CA. Perinatal consequences of maternal hypothyroidism in early pregnancy and inadequate replacement. Clin endocrinol Oxf. 1995; 42(4): 353-358.

29. Bishoi A., Sachmechi I. Thyroid disease during pregnancy. Am Fam Physician 1996; 53(1): 215-220.

30. Liu H., Momotani M., Noh JY et al. Maternal Hypothyroidism during early pregnancy and intellectual development of the progeny. Arch Intern Med 1994; 154(7): 785-787.

31. Pop VJ., de Vries E., Van Baar Al et al. Maternal thyroid peroxidase antibodies during pregnancy: a marker of impaired child development? J Clin Endocrinol Metab 1995; 80: 3561-3565.

32. Toft AD. Thyroxine therapy. N Engl J Med 1994; 21(3): 174-180.

33. Mc Dougall IR., Maclin N. Hypothyroid women need more thyroxine when pregnant. J Farm Pract 1995; 41(3): 238-240.

34. Mandel SJ., Reed Larsen P., Seely EW et al. Increased need for thyroxine in women with primary hypothyroidism $\mathrm{N}$ Engl J Med 1990; 323: 91-96.

35. Kaplan MM. Monitoring thyroxine treatment during pregnancy. Thyroid 1992; 2: 147-152.

36. Kaplan MM. Enfermedades tiroideas en el embarazo. Hipotiroidismo congénito. En: Gleisher N. Medicina Clínica en Obstetricia. Buenos Aires (Argentina). Editorial Médica Panamericana; 1989; 1: 25-258.

37. Brown RS., Belisario RL., Botero D et al. Incidence of transient congenital hypothyroidism due to maternal thyrotropin receptor blocking antibodies in over one millon babies. J Clin Endocrinol Metab. 1996; 81(3): 1147-1151.

38. Nicolini U., Venegoni E., Acaia B., Cortelazi B., Beck-Pecooz P. Prenatal treatment of fetal hypothyroidism: is there more than one option? Prenat Diagn 1996; 16(5): 443-448.

39. Abuhamad AZ., Fisher DA., Warsof Sl et al. Antenatal diagnosis and treatment of fetal goitrous hypothyroidism: case report and review of the literature. Ultrasound Obstet Gynecol 1995; 6(5): 368-371.

40. Hadi JA., Strickland D. In utero treatment of fetal goitrous hypothyroidism caused by matemal Grave's disease. Am J Perinatal 1995; 12(6): 455-458.

41. Van-Loon Aj., Derksen JT., Bos AF., Rouwe CW. In utero diagnosis and treatment of fetal goitrous hypothyroidism, caused by maternal use of propylthiouracil. Prenat Diagn 1995; 15(7): 599-604.

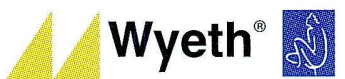

Lider mundial en el cuidado de la salud femenina 